\title{
Mathematical Model of Feet Temperature
}

\author{
David Bento*, Ana I. Pereira ${ }^{\dagger}$ and Fernando Monteiro* \\ ${ }^{*}$ Polytechnic Institute of Bragança, Portugal
Polytechnic Institute of Bragança, Portugal and ALGORITMI, Minho University, Portugal.
}

\begin{abstract}
In this work it is consider the problem of finding the best approximation to characterize the feet temperature distribution. For this study it was consider the nonlinear least squares technique, combined with penalty method, to identify the function that approximate better the data obtained through thermographic images. The preliminary results indicate that the best function approximation is based on trigonometric sums.
\end{abstract}

Keywords: Image processing. Nonlinear Optimization.

PACS: $02.60 . \mathrm{Pn}$

\section{INTRODUCTION}

Diabetic foot (DF) ulcers are one of the major complications in diabetics, seriously affecting the quality of their lives. The possibility to measure the different aspects of DF and its ulcerative pathology gives to clinicians the chance to both evaluate and weigh up the different components contributing to the genesis and evolution of the cases and to monitor their clinical course as a consequence of the therapeutic interventions. Therefore, it is necessary to establish methods of prevention or early diagnosis for diabetic foot complications [5].

Recent advances of physiological imaging techniques have prompted us to use thermography for screening skin temperature, deep tissue edema or fluid collection due to inflammation [5]. Infrared thermography is one of the leading technologies in use today. This technology is feasible for temperature monitoring of the foot and can be used as a complement to current practices for foot examinations in diabetes. In this study, we used thermal plantar images in patients without diabetes to support a mathematical model for foot temperature distribution.

The paper is organized as follows. Section 2 describes the materials and methods used in this study. Section 3 provides some numerical results and the last section presents some conclusions and ideas for future work.

\section{MATERIALS AND METHODS}

\section{Protocol}

This study includes healthy volunteers, recruited from Polytechnic Institute of Bragança, representing a feet healthy population who were between 21 to 43 years old.

The subjects were guided to keep resting supine position without shoes or socks for 10 minutes, before measurement, to stabilize the feet temperature. The images were collected by a thermal camera (FLIR 365) positioned at a fixed distance of 1 metre of subject's feet. A plate of rigid foam was placed over the ankles to isolate the temperature of feet from the rest of the body. The total duration of data acquisition process did not exceed 15 minutes.

\section{Method}

Consider the plantar image, $l$, obtained using a thermographic machine. For each thermographic image $l$, it was analyzed six different regions presented in the Figure 1.

For each region, $R_{k}^{l}$, for $k=1, \ldots, 6$, we obtained the matrix data with temperature distribution. 


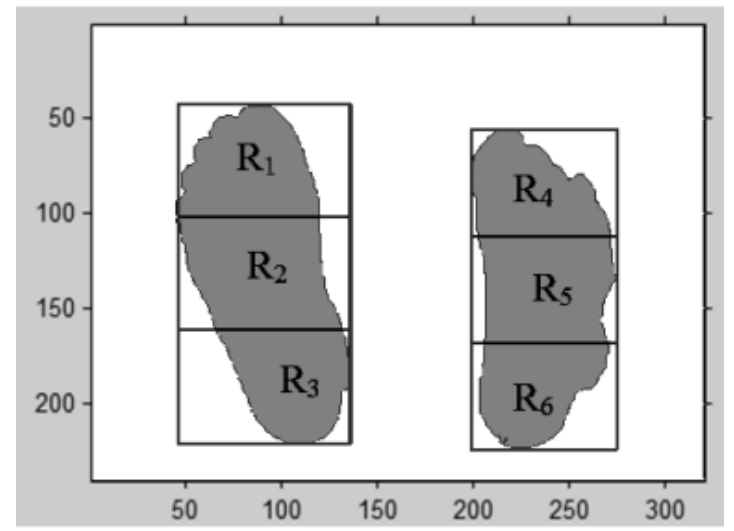

FIGURE 1. Feet regions.

In this study, we consider five nonlinear functions

$$
\begin{array}{ll}
f_{1}(x, i, j)=x_{1} i^{2}+x_{2} i j+x_{3} j^{2}+x_{5} i+x_{6} j+x_{7} ; & f_{2}(x, i, j)=x_{1} \sin \left(x_{2} i+x_{3}\right)+x_{4} \cos \left(x_{5} j+x_{6}\right)+x_{7} \\
f_{3}(x, i, j)=x_{1} \sin ^{2}\left(x_{2} i+x_{3}\right)+x_{4} \cos ^{2}\left(x_{5} j+x_{6}\right)+x_{7} ; & f_{4}(x, i, j)=x_{1} \sin \left(x_{2} i+x_{3}\right)+x_{4} \sin \left(x_{5} j+x_{6}\right)+x_{7}, \mathrm{e} \\
f_{5}(x, i, j)=x_{1} \sin ^{2}\left(x_{2} i+x_{3}\right)+x_{4} \sin ^{2}\left(x_{5} j+x_{6}\right)+x_{7} .
\end{array}
$$

The main objective is to identify what function is the best approximation for each region $R_{k}^{l}$, for $k=1, \ldots, 6$. For that, we need to solve, for each function $f_{w}$, for $w=1, \ldots, 5$, the following nonlinear constrained problem

$$
\begin{array}{ll}
\min & \sum_{i=1}^{N_{i}} \sum_{j=1}^{N_{j}}\left(t_{i j}-f_{w}(x, i, j)\right)^{2} \\
\text { s.t. } & f_{w}(x, i, j) \geq 0, \text { for }(i, j) \in R_{k}^{l}
\end{array}
$$

where $t_{i j}$ is the temperature matrix and $(i, j)$ represent the pixels positions.

To solve this problem we consider the nonlinear least squares method combined with penalty method.

We test five penalty functions to solve the problem (1). We consider the penalty function $l_{1}$ proposed by [4]; the quadratic penalty function, $l_{2}$, presented by [4]; the exponential penalty function, $E$, proposed by [2]; the hyperbolic penalty function, $H$, based on [6] and the dynamic penalty function, $D$, presented by [3].

\section{NUMERICAL RESULTS}

All proposed penalty methods were implemented in the Matlab Programming language on a Intel Core i3, CPU M330 $2.13 \mathrm{GHz}$, with $4.00 \mathrm{~GB}$ of RAM. The initial point was $x^{(0)}=[1, . ., 1]$.

The following table present the numerical results obtained with two plantar images. In Tables 1 and $2 l_{1}$ represents the numerical results obtained using $l_{1}$ penalty function, $l_{2}$ the quadratic penalty function and $H$ the hyperbolic penalty function.

The notations DS indicates that the method did not solve the problem and NF indicates that the method found a non feasible solution.

It is possible to observe that the best approximation function is based on a sum of trigonometric functions and with these results the best approximation was obtained with $f_{2}$. We also observed that the penalty methods based with exponential penalty function and the dynamic penalty function do not solved this type of problems. 
TABLE 1. Computational results for $l_{1}$ and $l_{2}$ penalty methods

\begin{tabular}{|c|c|c|c|c|c|c|c|c|c|c|}
\hline & & & $l_{1}$ & & & & & $l_{2}$ & & \\
\hline Region & $f_{1}$ & $f_{2}$ & $f_{3}$ & $f_{4}$ & $f_{5}$ & $f_{1}$ & $f_{2}$ & $f_{3}$ & $f_{4}$ & $f_{5}$ \\
\hline$R_{1}^{1}$ & $1.3 \mathrm{E}+6$ & $3.3 \mathrm{E}+6$ & $3.3 \mathrm{E}+6$ & $1.5 \mathrm{E}+6$ & $1.2 \mathrm{E}+6$ & $1.3 \mathrm{E}+6$ & $3.3 \mathrm{E}+6$ & $4.4 \mathrm{E}+6$ & $1.2 \mathrm{E}+6$ & $1.2 \mathrm{E}+6$ \\
\hline$R_{2}^{1}$ & $2.3 \mathrm{E}+6$ & $3.7 \mathrm{E}+6$ & $3.2 \mathrm{E}+5$ & $1.7 \mathrm{E}+6$ & $1.7 \mathrm{E}+6$ & $2.3 \mathrm{E}+6$ & $3.7 \mathrm{E}+6$ & $3.4 \mathrm{E}+5$ & $1.7 \mathrm{E}+6$ & $1.7 \mathrm{E}+6$ \\
\hline$R_{3}^{1}$ & $1.7 \mathrm{E}+6$ & $2.5 \mathrm{E}+6$ & $2.5 \mathrm{E}+6$ & $1.5 \mathrm{E}+6$ & $1.5 \mathrm{E}+6$ & $1.7 \mathrm{E}+6$ & $1.1 \mathrm{E}+6$ & $2.5 \mathrm{E}+6$ & $1.5 \mathrm{E}+6$ & $1.5 \mathrm{E}+6$ \\
\hline$R_{4}^{1}$ & $1.3 \mathrm{E}+6$ & $3.2 \mathrm{E}+6$ & $3.2 \mathrm{E}+6$ & $1.3 \mathrm{E}+6$ & $2.0 \mathrm{E}+6$ & $1.3 \mathrm{E}+6$ & $3.2 \mathrm{E}+6$ & $3.2 \mathrm{E}+6$ & $1.4 \mathrm{E}+6$ & $1.4 \mathrm{E}+6$ \\
\hline$R_{5}^{1}$ & $2.2 \mathrm{E}+6$ & $4.0 \mathrm{E}+6$ & $9.0 \mathrm{E}+5$ & $1.7 \mathrm{E}+6$ & $1.9 \mathrm{E}+6$ & $2.2 \mathrm{E}+6$ & $4.0 \mathrm{E}+6$ & $4.0 \mathrm{E}+6$ & $1.9 \mathrm{E}+6$ & $1.9 \mathrm{E}+6$ \\
\hline$R_{6}^{1}$ & $1.8 \mathrm{E}+6$ & $2.5 \mathrm{E}+6$ & $2.5 \mathrm{E}+6$ & $1.6 \mathrm{E}+6$ & $1.6 \mathrm{E}+6$ & $1.8 \mathrm{E}+6$ & DS & $2.5 \mathrm{E}+6$ & $1.5 \mathrm{E}+6$ & $1.5 \mathrm{E}+6$ \\
\hline$R_{1}^{2}$ & $1.2 \mathrm{E}+6$ & $3.1 \mathrm{E}+6$ & $1.9 \mathrm{E}+6$ & $1.3 \mathrm{E}+6$ & $1.4 \mathrm{E}+6$ & $1.1 \mathrm{E}+6$ & $1.3 \mathrm{E}+6$ & $1.9 \mathrm{E}+6$ & $1.2 \mathrm{E}+6$ & $1.9 \mathrm{E}+6$ \\
\hline$R_{2}^{2}$ & $2.4 \mathrm{E}+6$ & $1.4 \mathrm{E}+6$ & $2.0 \mathrm{E}+6$ & $2.1 \mathrm{E}+6$ & $2.1 \mathrm{E}+6$ & $2.4 \mathrm{E}+6$ & $1.4 \mathrm{E}+6$ & $2.1 \mathrm{E}+6$ & $2.1 \mathrm{E}+6$ & $2.1 \mathrm{E}+6$ \\
\hline$R_{3}^{2}$ & $2.6 \mathrm{E}+6$ & $4.9 \mathrm{E}+5$ & $2.0 \mathrm{E}+6$ & $2.0 \mathrm{E}+6$ & $2.0 \mathrm{E}+6$ & $2.6 \mathrm{E}+6$ & $4.9 \mathrm{E}+5$ & $2.0 \mathrm{E}+6$ & $2.0 \mathrm{E}+6$ & $2.0 \mathrm{E}+6$ \\
\hline$R_{4}^{2}$ & $1.2 \mathrm{E}+6$ & $3.2 \mathrm{E}+6$ & $9.5 \mathrm{E}+5$ & $9.5 \mathrm{E}+5$ & $9.5 \mathrm{E}+5$ & $1.2 \mathrm{E}+6$ & $8.1 \mathrm{E}+5$ & $1.7 \mathrm{E}+6$ & $9.5 \mathrm{E}+5$ & $8.3 \mathrm{E}+5$ \\
\hline$R_{5}^{2}$ & $2.0 \mathrm{E}+6$ & $2.6 \mathrm{E}+5$ & $1.7 \mathrm{E}+6$ & $1.7 \mathrm{E}+6$ & $1.7 \mathrm{E}+6$ & $2.0 \mathrm{E}+6$ & $3.6 \mathrm{E}+6$ & $1.5 \mathrm{E}+6$ & $1.6 \mathrm{E}+6$ & $1.5 \mathrm{E}+6$ \\
\hline$R_{6}^{2}$ & $2.0 \mathrm{E}+6$ & $2.8 \mathrm{E}+5$ & $1.6 \mathrm{E}+6$ & $1.6 \mathrm{E}+6$ & $1.7 \mathrm{E}+6$ & $2.0 \mathrm{E}+6$ & $9.7 \mathrm{E}+5$ & $1.6 \mathrm{E}+6$ & $1.6 \mathrm{E}+6$ & $1.6 \mathrm{E}+6$ \\
\hline
\end{tabular}

TABLE 2. Computational results for $H$ penalty methods

\begin{tabular}{c|ccccc}
\hline & \multicolumn{5}{|c}{$H$} \\
\hline Region & $f_{1}$ & $f_{2}$ & $f_{3}$ & $f_{4}$ & $f_{5}$ \\
\hline$R_{1}^{1}$ & $\mathrm{NF}$ & $\mathrm{DS}$ & $3.3 \mathrm{E}+6$ & $1.2 \mathrm{E}+6$ & $1.2 \mathrm{E}+6$ \\
$R_{2}^{1}$ & $\mathrm{NF}$ & $3.7 \mathrm{E}+6$ & $3.6 \mathrm{E}+6$ & $1.2 \mathrm{E}+6$ & $1.6 \mathrm{E}+6$ \\
$R_{3}^{1}$ & $\mathrm{NF}$ & $2.5 \mathrm{E}+6$ & $2.4 \mathrm{E}+6$ & $1.5 \mathrm{E}+6$ & $1.5 \mathrm{E}+6$ \\
$R_{4}^{1}$ & $\mathrm{NF}$ & $4.2 \mathrm{E}+5$ & $3.2 \mathrm{E}+6$ & $1.7 \mathrm{E}+6$ & $\mathrm{NF}$ \\
$R_{5}^{1}$ & $\mathrm{NF}$ & $4.0 \mathrm{E}+6$ & $4.0 \mathrm{E}+6$ & $1.4 \mathrm{E}+6$ & $\mathrm{NF}$ \\
$R_{6}^{1}$ & $\mathrm{NF}$ & $2.5 \mathrm{E}+6$ & $3.1 \mathrm{E}+5$ & $1.6 \mathrm{E}+6$ & $1.4 \mathrm{E}+6$ \\
\hline$R_{1}^{2}$ & $\mathrm{NF}$ & $3.1 \mathrm{E}+6$ & $1.1 \mathrm{E}+6$ & $\mathrm{NF}$ & $\mathrm{NF}$ \\
$R_{2}^{2}$ & $\mathrm{NF}$ & $3.7 \mathrm{E}+6$ & $1.7 \mathrm{E}+6$ & $\mathrm{NF}$ & $\mathrm{NF}$ \\
$R_{3}^{2}$ & $\mathrm{NF}$ & $3.7 \mathrm{E}+6$ & $1.4 \mathrm{E}+6$ & $\mathrm{NF}$ & $\mathrm{NF}$ \\
$R_{4}^{2}$ & $\mathrm{NF}$ & $8.2 \mathrm{E}+5$ & $9.7 \mathrm{E}+5$ & $9.5 \mathrm{E}+5$ & $9.5 \mathrm{E}+5$ \\
$R_{5}^{2}$ & $\mathrm{NF}$ & $3.6 \mathrm{E}+6$ & $1.5 \mathrm{E}+6$ & $\mathrm{NF}$ & $\mathrm{NF}$ \\
$R_{6}^{2}$ & $\mathrm{NF}$ & $9.1 \mathrm{E}+5$ & $1.3 \mathrm{E}+6$ & $\mathrm{NF}$ & $\mathrm{NF}$
\end{tabular}

\section{CONCLUSIONS AND FUTURE WORK}

High temperature gradients between foot regions may predict the onset of neuropathic ulceration, which makes temperature monitoring a way to reduce the risk of ulceration. 
This preliminary study indicates that the best mathematical model to approximate the temperature distribution is a trigonometric sum function. Future prospective observation is needed to confirm our mathematical model or some variation of it.

\section{REFERENCES}

1. D. Armstrong, K. Holtz-Neiderer, C. Wendel, Skin temperature monitoring reduces the risk for diabetic foot ulceration in high-risk patients, The American Journal of Medicine 120, pp. 1042-1046 (2007).

2. D. P. Bertsekas, Constrained Optimization and Lagrange Multiplier Methods, Athena Scientific (1996).

3. A. Correia, J. Matias, C. Serôdio, Métodos de penalidade exacta para resolução de problemas de optimização não linear, Investigação Operacional, 28, pp. 17-30 (2008).

4. J. Nocedal and S. Wright, Numerical Optimization, Springer Series in Operations Research, Springer (1999).

5. K. Nishide, T. Nagase, M. Oba, M. Oe, Y. Ohashi, S. Iizaka, G. Nakagami, T. Kadowaki and H. Sanada, Ultrasonographic and thermographic screening for latent imflammation in diabetic foot callus, Diabetes Research and Clinical Practice 85(3), pp. 304-309 (2009).

6. A. Xavier, Hyperbolic penalty: a new method for nonlinear programming with inequalities, International Transactions in Operational Research 8, pp. 659-671 (2001). 